\title{
The Moderating Effects of Gender Diversity on Supply Chain Practice and Firm Performance
}

\author{
Riaheen Farzana \\ Southern Illinois University Carbondale, Carbondale, US
}

\begin{abstract}
This research investivates the moderating effects of employees gender diversity and uncertainty on the relationship between supply chain practices and the performance of the firm which have a supply chain. Current supply chain management has become a possibly valuable way of improving firm performance. Gender plays an important role in the performance of an organization, but it has not get emphasize in research so far. This study provides a conceptual justification for a proposed model that identifies the relationships between supply chain practices and firm performance and describes the moderating effect of gender diversity and uncertainty. The higher levels of supply chain practice can lead to enhance firm performance. Also, gender diversity and uncertainty has an interaction effect on this relationship.
\end{abstract}

Keywords: supply chain practice, firm performance, gender diversity, uncertainty

Supply Chain is like nature, it is all around us

Dave Waters

We live in an interconnected world. There is competition all over the world. A company needs to produce quality products and services to get a competitive advantage. They can then sell those finished goods and services any places inside their home countries or export to other countries. It also helps customers to buy commodities and get services at their footsteps (Chin \& Tat, 2014). They don't even think about the origin or the location of the suppliers' company. The rapid growth of information technology accelerated this global process. These changes have helped customers to interact more and overcome language and time barriers.

This study attempts to examine the moderating effects of employees gender diversity and uncertainty on the relationship between supply chain practices and the performance of the firm which have a supply chain. Current supply chain management has become a possibly valuable way of improving firm performance. There are mainly five dimensions of supply chain management practice (strategic supplier partnership, customer relationship, the level of information sharing, quality of information sharing, and postponement) conceptualized and developed by Li, Ragu-Nathan, Ragu-Nathan, and Rao (2006).

Gender plays an important role in the performance of an organization, but it has not get emphasize in research so far. Many big name companies outsource their product from developing countries, where most of the employees are women. They take advantage of cheap labor by keeping women workers. Women workers produce high-quality brand products cheaply for global export. Not only in garment manufacturing sectors, but

Riaheen Farzana, Doctoral Candidate, Department of Management, Southern Illinois University Carbondale, Carbondale, USA. 
also in global food value chains, these workers play a significant role in selling high-value goods (Maertens \& Swinnen, 2012).

The growth of supply chain has a necessary and complex gender implication, especially in the developing countries. The traditional supply chain management concept considers the individual companies and elements within a firm as separate units that represent as functional entities (Maertens \& Swinnen, 2012). But the Modern Supply Chain (MSC) concept is more integrated and progressive than the traditional concept. Modern Supply Chains have improved their levels of integration across the entire supply chain, which comprises the production and selling of high-value products. These products are destined for export to high-income markets.

Flynn, Huo, and Zhao (2010) enrich the supply chain management study through extending the research by discussing the relationship between three dimensions of supply chain (customer, supplier, internal) integration, operational and business performance. They have applied contingency approach and configuration approach to analyzing those relationships. Maertens and Swinnen (2012) have contributed to a better understanding of gender and supply chain and implications of the growth in the modernization of the agriculture field. In their study, they mentioned that the integration of developing countries in global markets accelerated with increased participation in international trade and growing foreign direct investment inflows. This has resulted in a rapid change in developing countries agri-food systems with the rapid expansion of Modern Supply Chain. In the whole supply chain process, the internal and customer integration is more helpful than supplier integration to improve the performance (Flynn et al., 2010).

By reviewing the existing empirical evidence with survey-based evidence, Maertens and Swinnen (2012) discussed some techniques through which females are directly affected by the practice of supply chain. They conducted their survey-based empirical research on two high-value horticulture supply chains in Senegal. Modern Supply Chain has expanded rapidly in developing countries, which is based trade in agricultural commodities, such as fruits and vegetables, fish, poultry, and livestock, etc. The garment sector plays a vital role in some developing countries. The supply chain is a progressively important area of research in the globe and gender has a vital effect on this process.

Gender diversity and uncertainty may moderate the relationship between Supply Chain Management practices and performance of the garment industry of developing countries.

\section{Theoretical Foundation and Construct Development}

Gender has an integral role in supply chain management. This study attempts to examine the moderating role of gender and uncertainty on the relationship between supply chain practice and firm performance.

The research gap that has been found in the current literature are mainly, (i) lack of comprehensive view on different effect and interaction of gender on the supply chain, and (ii) lack of quantitative empirical analysis on gender and supply chain.

The growth of supply chain has a necessary and complex gender implication. After analyzing 400 Supply Chain Management articles, Chen and Paulraj (2004) have come up to the conclusion that Modern Supply Chain is one of the most significant paradigm shifts in management that the survival of solely autonomous entities is very difficult, but rather as supply chains. The positive aspect of globalization is women's expansion of paid employment opportunities in developing countries (Dejardin, 2009). But the challenge related to this is enhancing the security and quality of employment, reducing gender inequality. 


\section{Supply Chain Practice}

Supply Chain Practice includes a set of approaches and activities utilized by an organization to effectively integrate supply and demand for improving the management of its supply chain. The literature portrays supply chain practices from a variety of different perspectives with a common objective of ultimately improving the performance. Chen and Paulraj (2004) describe supply chain practices, which include supplier base reduction, long-term relationship, communication, cross-functional teams, and supplier involvement. In reviewing and consolidating the literature, Li et al. (2006) introduced the following five distinctive dimensions.

Strategic supplier partnership. It is the upstream sides of the supply chain. The relationship between the firm and its suppliers can be defined by this partnership.

Customer relationship. It is the downstream sides of the supply chain. The long-term relationship with customers and their satisfaction can be defined by this supply chain practice.

The level of information sharing. The measurement of the extent to which how much information can be shared with the supply chain partner.

The quality of information sharing. This is the information flow across a supply chain.

Postponement. It is an internal supply chain process. It allows a firm to be flexible in maintaining different versions of the goods to meet changing customer needs and demand.

\section{Firm Performance}

Firm performance refers to how well a firm achieves its ultimate objectives. It can be market-oriented goals as well as financial goals, or short-term goals (such as, increase productivity and reduce inventory holding and cycle time) as well as long-term goals (that is, increase market share and profits). Firm performance is a related concept in management research and regularly used as a dependent variable. Despite this significance, there is barely an agreement about its definition, dimensionality, and quantity, what restricts advances in research. The Modern Supply Chain has become a potential way of improving a firm's performance. There is a positive relationship between Modern Supply Chain practice and firm performance.

H1: Supply chain practice is positively related to the firm performance.

\section{Gender Diversity}

Gender has psychological or cultural connotations, rather than biological implications. If the term sex categorized with male and female, then gender will be masculine and feminine. The terms masculine and feminine are independent of biological sex. According to Stoller (1994), gender can define as the quantity of masculinity or femininity or the mixtures of both in a person. Usually, the typical male has a preponderance of masculinity and the female a preponderance of femininity.

"Role Congruity Theory of Prejudice Toward Female Leaders" builds on Social Role Theory (Eagly, 1995), which argues that women and men have historically filled different roles in work and the family, so they are expected to exhibit characteristics that particularly suit them for their respective role. There are two forms of prejudice: (a) viewing women less favorably than men as potential occupants of leadership positions and (b) measuring behavior that fulfills the requirements of a leader role less favorably when it is done by a woman (Eagly \& Karau, 2002, p. 573). Hoyt (2010) also found that women are still facing lots of difficulties than men in being perceived as a supreme leader.

There are two types of expectations or norms: (1) descriptive norms (what actually is), and (2) prescriptive 
or injunctive norms (what ought to be ideally). Gender roles are the collection of these two norms associated with women and men. Gender stereotypes follow from observations of people in sex-typical social functions. Stereotypes work as a barrier to women. Moreover, according to social role theory, these two attributes are related to beliefs about sexes, communal characteristics (associated with women and subordinated status), and agentic characteristics (associated with men and higher status). According to the role congruity theory, given the incongruence of being female with leadership, women have less potential to become a leader compare to men.

Koenig, Eagly, Mitchell, and Ristikari (2011) described three paradigms (think manager-think male, agency-communion, and masculinity-femininity paradigm) that demonstrated overall masculinity of leader stereotypes. But their research extends the role congruity theory in a new dimension, as they mentioned, stereotypes portrayed leaders as feminine in educational institutions than in other domains and moderate- than high-status leader roles. The increase of women leadership roles might produce less masculine and more genderless beliefs about leadership. Women leadership positions have grown mainly in some profession (nurses, teachers, receptionist, retail seller, etc.). In many countries, these are also visible in politics and business also. Hoyt and Burnette (2013) merge implicit theory with role congruity theory to extend their understanding go gender bias in leader evaluations.

Koenig et al. (2011) also mentioned that women are becoming more leaders now and changing the perceptions of leader roles. In developing countries, women emerge as leaders and entrepreneurs. Electing women for these roles not only perceives women as perfect leaders but also reduces their implicit bias toward association men with leadership. A recent Gallup poll (2011) has shown that people's preference for working for men has decreased from $46 \%$ to $32 \%$ and preference for working for women has increased from $19 \%$ to $22 \%$ in last 15 years. But the most interesting part is that no preference has raised melodramatically from 33\% to $44 \%$, which gives a positive indication of the same perception for the male and female boss (Hoyt \& Burnette, 2013).

The status of women empowerment relates to their economic position and social condition (Torri \& Martinez, 2014). Women empowerment' humanized service, distinctive personalities, observation, analytics, and social skills have played a great role in business. However related obstacles or challenges, women's involvement and outreach have also increased.

Schippers (2007) has introduced a model, where she explored the masculinity and femininity and their role in gender hegemony, which should focus on relationality. The answer to the question which could identify hegemonic or non-hegemonic masculinity and femininity is "Of those features and practices, which situate femininity as complementary and inferior to masculinity?” Answering this question can also identify the characteristics and practices valued in men or in women that don't naturalize and endorse a hierarchical bond between the masculine and feminine and males and females. In this study, the focus on masculinity and femininity is based on their features into practice, deployed as a rationale for practice, and institutionalized to establish and naturalize hierarchical and complementary social relationships between men and women.

Eagly, Karau, and Makhijani (1995) have found that there are no differences in the effectiveness of male and female leaders. But the interesting part is that they mentioned if the definition of leadership roles described in masculine terms, it favors male leaders, and if it defines in feminine terms, it supports female leaders. Peoples' perception will change if more women can enter the leadership or top management position. Eagly et al. (1995) have shown the impact of women leadership in different types of organization or settings. 
Gender diversity in management can impact firm performance in a way that, the more diversified the firm, the better the performance. Companies with more female in management position tend to gain better financial performance than the companies with a low number of women executives (Adler, 2001).

Several types of research have been done on gender diversity in social psychology and marketing literature. But the Supply Chain Management literature lacks major research into the interaction of gender diversity in the manufacturing industry and its effect on implementation on practices and performance. In view of the limited research on the diversity of gender in Supply Chain practices and firm performance, this study attempts to enhance the current understanding in this area. It is, therefore, hypothesized as follows:

H2: The positive effect of supply chain practice on the firm performance is moderated by gender diversity.

\section{Environmental Uncertainty}

Increased globalization and advances in information technology have an impact on gaining a competitive advantage of garment industries in developing countries. Global location planning is a very complex task for the company as they must evaluate environmental uncertainty. They need to consider the potential locations, potential customers, total cost, infrastructure, labor, political risk, governmental regulations, etc. Uncertainty is inherent to every supply chain in case of time-related to breakdown machines and vehicles, travel time, natural catastrophe, local politics, and different related issues. Still, the supply chain is significant when internal cost is minimized by reducing uncertainty.

H3: The positive effect of supply chain practice on the firm performance is moderated by environmental uncertainty.

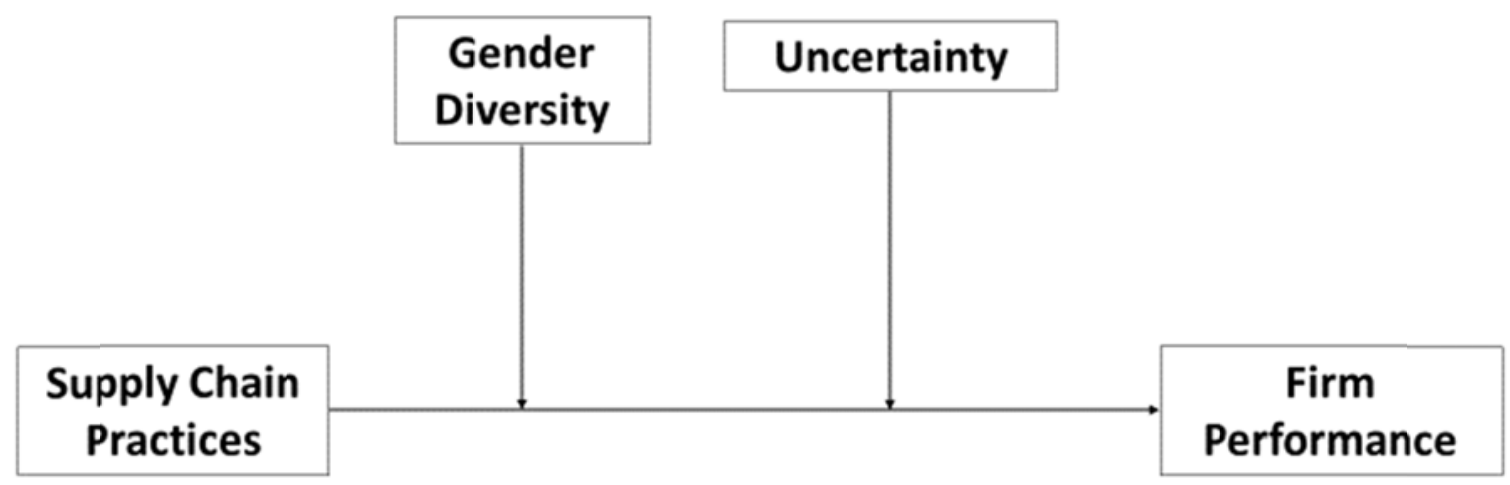

Figure 1. Proposed modle.

The conceptual framework has been developed in accordance to the research question generalized for this study, as shown in Figure 1. As seen in Figure 1, supply chain practices were the independent variable, firm performance was the dependent variable, whereas the moderating variable was gender diversity and uncertainty. Data for the research will be collected from the Garments Manufacturing Industry of Bangladesh. Though Bangladesh is a Least Developed Country, the garment industry is running excellent here. To measure the moderating role of gender diversity, Bangladesh will be the best place to collect data.

The relationships that proposed in the model will be tested using Structural Equation Modeling (SEM). The total model will be tested simultaneously in SEM. 


\section{Discussion}

The theoretical model illustrated in Figure 1 has three hypothesized relationships. Supply chain practice is positively related to firm performance because the firms with high levels of supply chain practice have high levels of firm performance ( $\mathrm{Li}$ et al., 2006). The implementation of supply chain management can have a bottom-line influence on the firm performance.

There were some manufacturing companies who practices supply chain management, where all the employees were male. Gender diversity in the workplace can change the work outcomes. Commitment, absenteeism, and turnover are some examples of work outcomes. Compare to women, men have the lower commitment and higher absenteeism rate in the workplace. For these reasons, men have more intention to work in a homogeneous group. Gender diversity changes the overall situation, with impact firm performance. Companies with more women in management lead to better financial and stock performance. Gender diversity can change as well as enhance the relationship between supply chain practice and firm performance.

Gender diversity of employees in the garments manufacturing company has a moderating effect on firm performance. The presence of gender diversity among employees with respect to performance could relate the fact that men and women are not similar in their supply chain practicing level. Perhaps gender diversity influences the relationships between supply chain practices and firm performance.

A linear relationship between supply chain practices and firm performance is sufficient in the case of garments manufacturing industries of Bangladesh.

The relationship changes with high environmental uncertainty. In an uncertain environment, the firm cannot perform its best. This study provides a conceptual evidence to support the hypothesis that environmental uncertainty can moderate the relationship between supply chain practices and firm performance.

\section{Practical Implications}

This study has an important implication practically. First, it discussed the supply chain practice elaborately and its relationship with firm performance.

Second, gender diversity is a new construct in supply chain research. This research shows the moderating effect of gender diversity on the relationship between supply chain practice and firm performance.

Third, this study will help those firms, who do not have proper knowledge of how to implement supply chain management.

Finally, this research supports the view that the manufacturing firms with high levels of supply chain practices can have high levels of performance.

\section{Limitations}

Lots of future opportunities are there to work on this topic. Due to time constraints, the revalidation of constructs was not carried out in this study. A systematic and quantitative research work can be done in future.

\section{Future Research}

Future research can be done empirically by collecting proper data from garments industry of Bangladesh. The concept of supply chain management is complex and involves a network of companies, but the final output of the model, firm performance can be measured with the help of aggregate data of manufacturing firms of Bangladesh. 
Future study can also test the intra-relationship among all the dimensions of supply chain practices. Moreover, the study will be more effective if we can find out there is any other moderating factor, which can affect the relationship between supply chain practices and firm performance.

\section{Conclusion}

The supply chain practices of having dense ties with customer and supplier were found to be the most relevant factor in improving firm performance. Besides, gender diversity and uncertainty played a moderation role in supply chain practices and firm performance link.

This study provides a conceptual justification for a proposed model that identifies the relationships between supply chain practices and firm performance and describes the moderating effect of gender diversity and uncertainty.

The higher levels of supply chain practice can lead to enhance firm performance. Also, gender diversity and uncertainty has an interaction effect on this relationship.

\section{References}

Adler, R. D. (2001). Women in the executive suite correlate to high profits. Harvard Business Review, 79(3), 131-137.

Chen, I. J., \& Paulraj, A. (2004). Towards a theory of supply chain management: The constructs and measurements. Journal of Operations Management, 22(2), 119-150.

Chin, T. A., \& Tat, H. H. (2014). Does gender diversity moderate the relationship between supply chain management practice and performance in the electronic manufacturing services industry? International Journal of Logistics Research and Applications, 18(1), 35-45.

Dejardin, K. A. (2009). Gender (in) equality, globalization, and governance. Working Paper No. 92. Retrieved from https://www.ilo.org/wcmsp5/groups/public/---dgreports/---integration/documents/publication/wcms_108648.pdf

Eagly, A. H. (1995). The science and politics of comparing women and men. American Psychologist, 50(3), 145-158.

Eagly, A. H., \& Karau, S. J. (2002). Role congruity theory of prejudice toward female leaders. Psychological Review, 109(3), 573-598.

Eagly, A. H., Karau, S. J., \& Makhijani, M. G. (1995). Gender and the effectiveness of leaders: A meta-analysis. Psychol Bull, 117(1), 125-145.

Flynn, B. B., Huo, B., \& Zhao, X. (2010). The impact of supply chain integration on performance: A contingency and configuration approach. Journal of Operations Management, 28(1), 58-71.

Hoyt, C. L. (2010). Women, men, and leadership: Exploring the gender gap at the top. Social and Personality Psychology Compass, 4(7), 484-498.

Hoyt, C. L., \& Burnette, J. L. (2013). Gender bias in leader evaluations merging implicit theories and role congruity perspectives. Personality and Social Psychology Bulletin, 39(10), 1306-1319.

Koenig, A. M., Eagly, A. H., Mitchell, A. A., \& Ristikari, T. (2011). Are leader stereotypes masculine? A meta-analysis of three research paradigms. Psychological bulletin, 137(4), 616.

Li, S., Ragu-Nathan, B., Ragu-Nathan, T. S., \& Rao, S. S. (2006). The impact of supply chain management practices on competitive advantage and organizational performance. Omega, 34(2), 107-124.

Maertens, M., \& Swinnen, J. F. (2012). Gender and modern supply chains in developing countries. The Journal of Development Studies, 48(10), 1412-1430.

Schippers, M. (2007). Recovering the feminine other: Masculinity, femininity, and gender hegemony. Theory and Society, 36(1), 85-102.

Stoller, R. J. (1994). Sex and gender: The development of masculinity and femininity. London: Karnac Books.

Torri, M. C., \& Martinez, A. (2014). Women's empowerment and micro-entrepreneurship in India: Constructing a new development paradigm? Progress in Development Studies, 14(1), 31-48. 